\title{
Skill Development of Undergraduate Students through International Exchange Program
}

\author{
Md Kamrul Hossain ${ }^{1}$ \\ Md. Fokhray Hossain ${ }^{1}$ \\ Mohamed Emran Hossain ${ }^{1}$ \\ A. K. M. Fazlul Hoque ${ }^{1}$ \\ Nafis M. Khan ${ }^{1}$ \\ Anton Abdulbasah Kamil ${ }^{2}$ \\ ${ }^{1}$ Daffodil International University, \\ Daffodil Smart City, Dhaka, \\ Bangladesh \\ ${ }^{2}$ Istanbul Gelisim University, Cihangir, \\ Sehit Jandarma Komando, J. Kom. \\ Er Hakan Öner Sk. No:1, 34310 Avclar, \\ Istanbul, Turkey
}

DOI: https://doi.org/10.36941/jesr-2022-0033

\section{Abstract}

The international exchange program plays an important role in improving soft skills and helps graduates' to be confident to compete in job market. Student can achieve a vast academic knowledge apart from extracurricular and co-curricular skills through attending exchange program. Therefore, this paper aims at studying the development of students acquired soft skills and the barriers they face to achieve the goal through the exchange program. The data obtained from 87 students who participated in exchange program in different countries of Asia. Besides descriptive statistics, factor analysis was performed to identify the achieved soft skills through exchange program. This study reveals that, a large number of students were attending in exchange program at their own cost and most of the students were from the year 3. Indubitably, Exchange program helps to improve students' soft skill such as; communication skill, team building ability, adaptability with situation. Moreover, lectures delivered to the students were found interesting. Results of the study are expected to motivate students attending in international exchange program and will offer a right direction to the students to get an expected outcome

Keywords: Collaboration, Exchange Program, Factor Analysis, Soft Skills 


\section{Introduction}

Learning is a complex process because of individual's ability to learn and way of learning. The goal of learning is to make sense of and using new information and experiences. During student life a student can get experience of new information from his/her institution as well as more experience of technology and culture can be gathered through exchange program. A student from developing country like Bangladesh some time spends a lot to attend in the exchange program for gather more experience and knowledge. However, there is no literature to find the impact of exchange program on the Bangladeshi students through exchange program. According to Earley et. al. (2006), cultural intelligence signifies the ability to adopt with new culture, gaining cross-cultural knowledge through knowing how things are operated nationally and internationally. Therefore, international experience is working as the key force of increasing cultural intelligence (Thomas \& Inkson, 2004). Now days, Employers are focusing to recruit the employees who have a good understanding about cultural issues, ability to manage international relationships and know how to adopt with diverse workforce beside subjective knowledge [Earley, et. al. (2006), Atalar (2020), Ledwith \& Seymor (2001), Mak, et.al. (1999)]. In the same way, academic institutions have acknowledged the significance of global perspective by introducing international elements into their program outcome [Harvey \& BowersBrown (2004), Cranmer (2006)].

The term internationalization and globalization can be described in various ways (Knight, (1997), (2004)]. In this study, internationalization is defined as a systematic way that required continuous efforts to strengthen the relationships between national cultures (Crossman \& Clarke, 2010). On the other hand, globalization denotes itself as the world system (Marginson, 200o) that emphasizes upon homogeneity (Gosling \& Mintzberg, 2003). Therefore, business is not limited within a nation and as a result, it has to be connected with international suppliers or customers and, the companies demanding employees who have such abilities [Gupta \& House, (2004), Rossen, et.al. (2000), Stohl (2001)]. Literatures show that, the ability of working with intercultural teams has a positive impact on critical thinking, ability to solve problem, decision making, creative and innovation, communication, cooperation and financial managment [Cacioppe, (1998), De Anca \& Va'zquez (2007), Dubrin, et. al. (2006), Tung \& Thomas (2003)].

The universities are promoting internationalization of their curriculum for the students over the years (Webb, 2005). In order to create balanced graduate, universities as "cultural institutions" are adopting frequent changing context including culture for making positive contributions to students (Welch \& Denman, 1997). However, the internationalization in universities has been exaggerated since 1950's to respond cultural forces associated with global economy [Welch \& Denman (1997), Goby (2007)]. Among the area of internationalization, international exchange programs are being frequently promoted among the students of universities [Hermans (2007), Leask (2007)].

It was Australia who first introduced international exchange program to Asian nations as a symbol of peace and expansion of trade (Davis et al. 1999). ERASMUS was launched in 1987 with the hope of staff and student mobility within the universities (Welch \& Denman, 1997). The Success of ERASMUS not only inspired Australia to offer University Mobility in Asia and the Pacific (UMAP) but also leaded Australian youth ambassadors for development programmer, AIESEC for better cultural understandings (Davis, et. al, 1999). Realizing the effect of exchange program, Colleges and Universities of USA also offered exchange program for the intensification of internationalization (Crossman \& Clarke, 2010).

According to Hillage \& Pollard (1998) and Rothwell \& Arnold (2007), employability are the skills and abilities which help a graduate to be employee or continuing employment. Graduate employability is one of the key parameters to evaluate performance of both an individual and an institutional level (Harvey, 2001). That is why; the universities are focusing and offering subject oriented knowledge, effective knowledge, skills as well as attitudes to its graduates [Leckey \& McGuigan (1997), Cox \& King (2006)]. Effective knowledge is the responsibility, positive to work, ability to work as a team as well as independently and interpersonal skills (Cassidy, 2006). It is 
expected that, international exchange program would be able to increase knowledge transfer and develop competencies among the graduates [Di Pietro (2015), Chan \& Dimmock (2008), Teichler (2004)]. Moreover, international experience has impact on learning and adoptability of cultural sensitivity, personal and professional development which influences employability (Osland, 2008). Przytuła et al. (2020) found that exchange program filled the cross culture gap. Handayani and Wienanda (2020) showed that international exchange program improved soft skill of the students. Roy et al. (2019) classified the learning outcome through exchange program into three categories cultural outcome, personal outcome and career outcome.

Nowadays undergrad students from Bangladesh are also joining in various international exchange program. Bangladeshi students are attending international exchange program in a regular basis however, the impact of this program on the participants is still hardly found in literature. Thus, the objective of the study is to evaluate students' perception regarding acquisition of soft skill through international exchange program.

\section{Methodology}

This study is a cross sectional study to explore the skill achieved through exchange program.

\subsection{Data Collection}

Data were collected from the students who participated in different exchange programs through mail. A number of 87 students of different universities of Bangladesh were interviewed with a semi structured questionnaire. The questionnaire was finalized after pilot test and based on expert opinion.

A total of 500 students participated in exchange program were requested to participate in the survey, therefore, the response rate is over $17 \%$. Email interview usually gets a low response [Manfreda, et. all. (2008), Tuten (1997), Jones \& Pitt (1999)].

\subsection{Analytical Tools}

Descriptive statistical analysis was used to explore the personal determinants of attending in exchange program and factor analysis was used to explore the achieved soft skills through exchange program.

\subsection{Factor Analysis}

Factor analysis is a statistical analysis for reducing variables into fewer. Goal of the analysis is to maximizing the common variance from all variables and keep the variables into a common score. Though different types of methods can be applied to extract the factors, this study used principal component analysis.

\subsection{Principal Component Analysis (PCA)}

PCA, at first, formed a factor which maximizing variance of the variables. After that, the variance explained by the first factors is removed and then again maximizing variance of the variables to form second factor. The process continue till forming the last factor.

\subsection{Factor loading}

Factor loading is the correlation between the study variable and factor. Factor loading indicates the variance explained by the variable of the particular factor. 


\subsection{Eigenvalues}

Eigenvalues is also called characteristic roots. Eigenvalues indicates variance explained by the factor out of the total variance.

\subsection{Factor score}

Factor score is the row and columns, which can be used as an index of all variables and can be used for further analysis.

\subsection{Criteria for determining the number of factors}

According to the Kaiser Criterion, the eigenvalue greater than 1 is a good criterion to select a factor and this study selected such 4 factors.

\subsection{Rotation method}

Among the different rotation method, varimax rotation method was used in the study for maximizing the squared correlation of items related to the factor.

\section{Result and Discussion}

\subsection{Background characteristics of the participants}

In Table 1 it is found that, among the respondents $54 \%$ were female and more than $56 \%$ participants were from first and second year of their academic session. About $87 \%$ participants were attendant in the less than 2 week's duration of exchange program.

Most of them (94.3\%) have communication with their friends with whom introduce during the program. More than $54 \%$ respondents were attended using their own fund. About $57 \%$ respondents were using Facebook as a medium of communication with their friends of exchange program, whereas $26 \%$ wire using WhatsApp as a tool of communication (Fig 1).

Table 1: Characteristics of the participants who attended in exchange program

\begin{tabular}{|l|l|c|}
\hline Variables & Categories & $\begin{array}{c}\text { Number of } \\
\text { students (\%) }\end{array}$ \\
\hline \multirow{2}{*}{ Gender } & Male & $40(46.0)$ \\
\cline { 2 - 3 } & Female & $47(54.0 \%)$ \\
\hline \multirow{2}{*}{ Academic Year } & less or 2 ${ }^{\text {nd }}$ year & $49(56.3 \%)$ \\
\cline { 2 - 3 } & $3^{\text {rd }}$ year or more & $38(43.6 \%)$ \\
\hline \multirow{2}{*}{ Duration of the program } & Less than or equal 2 weeks & $76(87.5 \%)$ \\
\cline { 2 - 3 } & More than 2 weeks & $11(12.5 \%)$ \\
\hline \multirow{2}{*}{ Connected with program friends } & Yes & $82(94.3 \%)$ \\
\cline { 2 - 3 } & No & $5(5.7 \%)$ \\
\hline \multirow{2}{*}{ First visit to abroad } & Yes & $74(85.1 \%)$ \\
\cline { 2 - 3 } & No & $13(14.9 \%)$ \\
\hline \multirow{2}{*}{ Funded Status } & Self-funded & $28(54.2 \%)$ \\
\cline { 2 - 3 } & Partially funded & $12(32.1 \%)$ \\
\cline { 2 - 3 } & Fully funded & \\
\hline
\end{tabular}




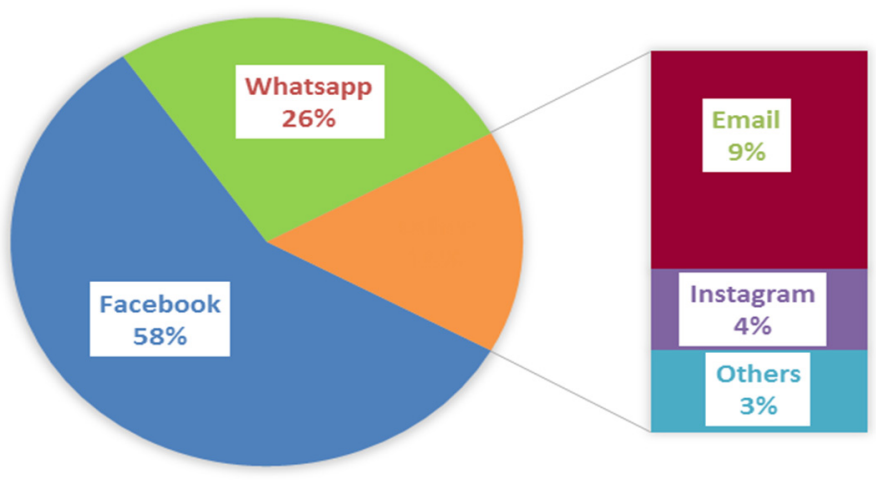

Figure 1: Medium of communication used to connect with program friends

\subsection{Criteria for the appropriateness of Factor Analysis}

Table 2 represents the adequateness of the sample and validity of factor analysis of the data. Kaiser Mayer Olkin measure represents that the sample size is adequate to run the factor analysis as the value is $0.839(>0.6)$.

Table 2: KMO and Bartlett's Test

\begin{tabular}{|c|c|c|c|}
\hline \multirow{2}{*}{ Kaiser-Meyer-Olkin Measure } & \multicolumn{3}{|c|}{ Bartlett's Test } \\
\cline { 2 - 4 } & Approx. Chi-Square & Degree of freedom & P value \\
\hline 0.839 & 815.38 & 153 & 0.001 \\
\hline
\end{tabular}

Bartlett's test indicates that correlation matrix is not an identity matrix as $\mathrm{p}$ value $<0.01$. There is no perfect correlation between the items (Appendix Table $\mathrm{Al}_{1}$ ) though they may significant. Thus, all the criteria are indicating that, it is possible to run factor analysis for the data.

\subsection{Factors extraction}

Table 3 presents the percent of total variation which is explained by each component. It is observed that, first four variable has eigenvalue more than 1 . And these variables can explain about $65 \%$ variation of the total. That is, the components can be reduced into four components. The observed variables are categories into the latent component based on the highest loadings for a component.

Table 3: Total variance explained by the factors

\begin{tabular}{|c|c|c|c|c|c|c|}
\hline \multirow{2}{*}{ Component } & \multicolumn{3}{|c|}{ Extraction Sums of Squared Loadings } & \multicolumn{3}{c|}{ Rotation Sums of Squared Loadings } \\
\cline { 2 - 7 } & Total & Variance (\%) & Cumulative (\%) & Total & $\begin{array}{c}\text { Variance } \\
(\%)\end{array}$ & $\begin{array}{c}\text { Cumulative } \\
(\%)\end{array}$ \\
\hline 1 & 7.20 & 39.99 & 39.99 & 4.52 & 25.131 & 25.131 \\
\hline 2 & 2.01 & 11.18 & 51.18 & 2.83 & 15.742 & 40.873 \\
\hline 3 & 1.48 & 8.22 & 59.39 & 2.54 & 14.136 & 55.009 \\
\hline 4 & 1.01 & 5.61 & 64.99 & 1.80 & 9.985 & 64.994 \\
\hline
\end{tabular}

Note: Only the selected components are present in the table

The four components can be defined as personal skills teaching method collaboration and 
satisfaction were the achievement for attendee from an exchange program (Table 4). Timlin (2017) found that, the exchange program is developing students' personal, civic, academic, and professional skills. The personal skills are the linear combination of different culture acquisition, learn how to face real life problem, teamwork skill, adaptation with situation, understanding global job market requirement (Petzold, 2017), communication skills, self-esteem presentation skill.

Table 4: Rotated Component Matrix

\begin{tabular}{|c|c|c|c|c|c|}
\hline \multirow[t]{2}{*}{ Latent Component } & \multirow[t]{2}{*}{ Observed variables } & \multicolumn{4}{|c|}{ Component } \\
\hline & & 1 & 2 & 3 & 4 \\
\hline \multirow[t]{8}{*}{ Personal Skill } & Different culture acquisition & 0.81 & 0.19 & 0.04 & 0.07 \\
\hline & Learn to face practical life related challenges & 0.76 & 0.15 & 0.31 & -0.08 \\
\hline & Teamwork & 0.75 & 0.11 & 0.22 & -0.24 \\
\hline & Adaptation with situation & 0.72 & 0.13 & 0.27 & -0.12 \\
\hline & Global market requirement & 0.70 & 0.28 & 0.20 & 0.29 \\
\hline & Communication skill & 0.60 & 0.34 & 0.16 & 0.45 \\
\hline & Self esteem & 0.59 & 0.15 & 0.58 & -0.05 \\
\hline & Interpersonal presentation skill & 0.58 & 0.32 & 0.27 & 0.16 \\
\hline \multirow[t]{3}{*}{ Teaching Method } & Lecture are interesting & 0.13 & 0.77 & 0.24 & -0.13 \\
\hline & Learning with fun & 0.28 & 0.59 & 0.17 & 0.14 \\
\hline & Academic knowledge with proper example & 0.10 & 0.53 & 0.46 & -0.01 \\
\hline \multirow[t]{3}{*}{ Collaboration } & Friendship develop & 0.39 & 0.13 & 0.82 & -0.26 \\
\hline & Peer group to solve problem & 0.35 & -0.01 & 0.76 & 0.01 \\
\hline & Helpful to each other & 0.38 & 0.20 & 0.70 & -0.07 \\
\hline \multirow[t]{4}{*}{ Satisfaction } & Satisfy with the arrangement & 0.07 & 0.43 & -0.03 & 0.69 \\
\hline & Effective for learning & 0.02 & -0.23 & -0.02 & 0.81 \\
\hline & Do not feel boar & -0.12 & 0.41 & -0.11 & 0.72 \\
\hline & Want to suggest friends to join in exchange program & 0.37 & 0.34 & 0.06 & 0.71 \\
\hline
\end{tabular}

In exchange program, the participants found the classrooms a very interesting place of teaching and learning are filled with fun and enjoyed the lecture which was delivered with an appropriate example and eventually, students got interest in it. Miglietti (2015) also found that, international educational exchange had a significant impact on teaching in the classroom. According to their perception, this is a platform offers students' with great opportunity for collaboration that leads to friendship development group to solve problem and help each other. Sato, et. al. (2018) also expressed that international exchange among Asian youths would contribute to understand each other lifestyle. The participants were satisfied with the exchange program due to its' perfect arrangement and making the environment - a place of effective learning which raises interest in them to join again as well as to suggest their friend to join in exchange program.

\section{Conclusion}

The social media should consider as a media of communication to collect information or data. Facebook, a very common and popular social media can play significant role to collect data or information quickly rather than any other digital communication media or traditional methods. Study reveals that, $58 \%$ of respond of exchange students' priority go to Facebook as communication media whereas, the priority of other respond is $26 \%$ through WhatsApp, $9 \%$ through email, $4 \%$ through Instagram and 3\% for other way of communication.

It is found that $32.1 \%$ students are participated in exchange program through partial-funded and $13.7 \%$ students are fully-funded to participate international exchange program.

It should be mentioned here that, the $70 \%$ of the students of Daffodil International University (DIU) are from the rural areas of Bangladesh whose socio-economic status is not that much solvent. 
That's why, many meritorious and insolvent students are not getting the opportunity to join the international exchange program due to pecuniary troubles. The findings of this research also express and indicate that, concentration should be given to the meritorious and insolvent students so that they could get the opportunity to attend in international exchange program with full funded scholarship or full grant from government or non-government organization for the betterment of the nation.

The significant achievement of student exchange program is to enhance the personal skills, interpersonal skills, communication skills, and soft skills, know the techniques and approaches and methods of teaching, collaboration or making friendship with the global student, increase their global network to learn foreign culture and experience. Therefore, it can be claimed that, if an institute or community wants to create graduate for global job market with soft skills along with their academic knowledge needs to involve their students with international exchange program.

\section{References}

Atalar, A. (2020). Student Exchange: The First Step Toward International Collaboration. In Successful Global Collaborations in Higher Education Institutions (pp. 63-71). Springer, Cham

Cacioppe, R. (1998). "An integrated model and approach for the design of effective leadership development programs." Leadership and Organization Development Journal 19(1): 44-53.

Cassidy, S. (2006). "Developing employability skills: Peer assessment in higher education." Education and Training 48(7): 508-517.

Chan, W., \& Dimmock, C. (2008). "The internationalisation of universities. Globalist, internationalist and translocalist models." Journal of Research in International Education 7(2): 184-204.

Cox, S., \& King, D. (2006). "Skill sets: An approach to embed employability in course design." Education and Training 48(4): 262-274.

Cranmer, S. (2006). "Enhancing graduate employability: Best intentions and mixed outcomes." Studies in Higher Education 31(2): 169-184.

Crossman, J. E., \& Clarke, M. (2010). "International experience and graduate employability: Stakeholder perceptions on the connection." Higher education 59(5): 599-613.

Davis, D., Milne, C., \& Olsen, A. (1999). Becoming internationally competitive: The value of international experience for Australian students. Canberra: IDP Education Australia.

De Anca, C., \& Va'zquez, A. (2007). Managing diversity in the global organization. Creating new business values. (trans: Andy Goodall). New York: Palgrave Macmillan.

Di Pietro, G. (2015). "Do study abroad programs enhance the employability of graduates?". Education Finance and policy 10(2): 223-243.

Dubrin, A., Dalglish, C., \& Miller, P. (2006). Leadership. Milton, Qld: Wiley.

Earley, P., Soon, A., \& Tan, J. (2006). Developing cultural intelligence at work. Stanford, California: Stanford Business Books.

Goby, V. (2007). "Business communication needs." Journal of Business and Technical Communication 21(4): 425-437.

Gosling, J., \& Mintzberg, H. (2003). "The five minds of a manager." Harvard Business Review 81(11): 54-63.

Harvey, L. (2001). "Defining and measuring employability." Quality in Higher Education 7(2): 97-109.

Harvey, L., \& Bowers-Brown, T. (2004). "Employability cross country comparisons." Graduate Market Trends Winter 2004/5.

Hermans, J. (2007). “High potentials: A CEO perspective." Journal of Studies in International Education 11(3/4): $510-521$.

Hillage, J., \& Pollard, E. (1998). Employability: Developing a framework for policy analysis. DFEE. London: Department for Education and Employment.

Jones, R. \& Pitt, N. (1999). "Health surveys in the workplace: comparison of postal, email and world wide web methods.” Occupational Medicine 49 (8): 556-558.

Knight, J. (1997). Internationalization of higher education: a conceptual framework. In J. Knight \& H. de Wit (Eds.), Internationalization of higher education in Asia Pacific countries. Amsterdam: EAIE/IDP.

Knight, J. (2004). "Internationalization remodeled: Definition, approaches, and rationales." Journal of Studies in International Education 8(1): 5-31. 
Leask, B. (2007). Chapter 8 Internationalization of the curriculum in an interconnected world. In G. Crosling, L. Thomas, \& M. Heagney (Eds.), Improving student retention in higher education-The role of teaching and learning (pp. 95-101). Routledge: Abingdon.

Leckey, J. F., \& McGuigan, M. A. (1997). "Right tracks-Wrong rails: The development of generic skills in higher education.” Research in Higher Education 38(3): 365-378.

.Ledwith, S., \& Seymor, D. (2001). "Home and away: Preparing students for multicultural management." International Journal of Human Resource Management 12(8): 1292-1312.

Manfreda, K. L., Berzelak, J., Vehovar, V., Bosnjak, M., \& Haas, I. (20o8). "Web Surveys versus other Survey Modes: A Meta-Analysis Comparing Response Rates.” International Journal of Market Research 50(1): 79-104. doi:10.1177/147078530805000107

Mak, A., Barker, M., Logan, G., \& Millman, L. (1999). Benefits of cultural diversity for international and local students: Contributions from an experiential social learning program (The Excel Program). In D. Davis \& A. Olsen (Eds.), International education: The professional edge, a set of research papers presented at the 13 th Australian International Education Conference. Freemantle: Education Australia.

Marginson, S. (200o). "Rethinking academic work in the global era." Journal of Higher Education Policy and Management 22(1): 23-35.

Miglietti, C. (2015). "Teaching business classes abroad: How international experience benefits faculty, students, and institutions." Journal of Teaching in International Business 26(1): 46-55.

Osland, J. (2008). Overview of the global leadership literature. In M. Mendenhall, J. Osland, A. Bird, G. Oddou, \& M. Maznevski (Eds.), Global leadership. Research, practice and development (pp. 34-64). London: Routledge.

Petzold, K. (2017). "The role of international student mobility in hiring decisions. A vignette experiment among German employers." Journal of Education and Work 30(8): 893-911.

Rossen, R., Digh, P., Singer, M., \& Phillips, C. (200o). Global literacies. New York: Simon and Schuster.

Rothwell, A., \& Arnold, J. (2007). “Self-perceived employability development and validation of a scale.” Personnel Review, 36(1): 23-41.

Sato, F., Kitajima, K., \& Kuga, A. (2018). Seeking alternative lifestyles via international exchange. A report on the Rikkyo-Hallym program in Ogawa, Saitama, \& Tokyo.

Stohl, C. (2001). Globalizing organizational communication. In F. Jablin \& L. Putnam (Eds.), The new handbook of organizational communication. Accessing theory, research and methods. Thousand Oaks: Sage.

Teichler, U. (2004). "The changing debate on internationalisation of higher education." Higher Education 48: 526.

Thijssen, G. L., Van Der Heijden, B. I. J. M., \& Rocco, T. S. (2008). “Toward the employability link model: Current employment transition to future employment perspectives.” Human Resource Development Review 7(2): $165^{-183}$.

Thomas, D., \& Inkson, K. (2004). Cultural intelligence. People skills for global business. San Francisco: BerrettKoehler Publishers.

Timlin, K. (2017). The Factors Influencing the Achievement of a US Governmentally-Sponsored International Education Exchange Program's Objectives: Reflections of Alumni from the Kyrgyz Republic. Retrieved from the University of Minnesota Digital Conservancy, http://hdl.handle.net/11299/191429.

Tung, R., \& Thomas, D. (2003). Human resource management in a global world: The contingency framework extended. In D. Tjosvold \& L. Kwok (Eds.), Cross-cultural management. Foundations, future. Hampshire, England: Ashgate.

Tuten, T.L. (1997). Getting a Foot in the Electronic Door: Understanding Why People Read or Delete Electronic Mail (Rep. No. 97/o8). Mannheim: Zentrum für Umfragen, Methoden und Analysen.

Gupta, V., \& House, R. J. (2004). "Understanding Leadership in Diverse Cultures: Implications of Project GLOBE for Leading International Ventures," World Scientific Book Chapters, in: Dean Tjosvold \& Kwok Leung (ed.), Leading In High Growth Asia Managing Relationship for Teamwork and Change, chapter 2, pages 13-54, World Scientific Publishing Co. Pte. Ltd.

Webb, G. (2005). Internationalization of curriculum. An institutional approach. In J. Carroll \& J. Ryan (Eds.), Teaching international students. Improving learning for all. Abingdon, Oxford: Routledge.

Welch, A., \& Denman, B. (1997). "Internationalization of higher education: Retrospect and prospect." Forum of Education 52: 14-29.

Przytuła, S., Bruska, A., Szymańska-Czaplak, E., \& Tracz-Krupa, K. (2020). Enhancing Cross-Cultural Competence Among Students in an Effort to Fill the Skills Gap in the European Labor Market. In Faculty of Tourism and Hospitality Management in Opatija. Biennial International Congress. Tourism \& Hospitality Industry (pp. 202-215). University of Rijeka, Faculty of Tourism \& Hospitality Management. 
Handayani, A., \& Wienanda, W. K. (2020). International Mobility Programs to Improve Soft Skills of Vocational College Students and Alumni. Journal of Education and Learning (EduLearn), 14(3), 377-384.

Roy, A., Newman, A., Ellenberger, T., \& Pyman, A. (2019). Outcomes of international student mobility programs: a systematic review and agenda for future research. Studies in Higher Education, 44(9), 1630-1644.

Appendix: Table A1. Correlation matrix between items

\begin{tabular}{|c|c|c|c|c|c|c|c|c|c|c|c|c|c|c|c|c|c|c|}
\hline & 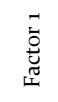 & 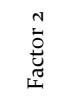 & 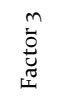 & 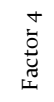 & 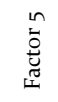 & 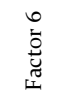 & 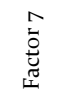 & 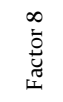 & $\begin{array}{l}a \\
\overrightarrow{0} \\
\mathbb{0} \\
\text { I }\end{array}$ & 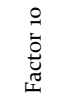 & 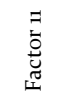 & 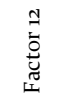 & 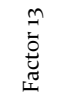 & 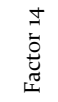 & $\begin{array}{l}n \\
\stackrel{n}{0} \\
\stackrel{0}{0} \\
\text { I }\end{array}$ & 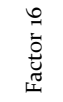 & 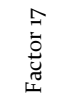 & 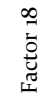 \\
\hline Factor 1 & 1.00 & & & & & & & & & & & & & & & & & \\
\hline Factor 2 & 0.03 & 1.00 & & & & & & & & & & & & & & & & \\
\hline Factor 3 & 0.43 & 0.14 & 1.00 & & & & & & & & & & & & & & & \\
\hline Factor 4 & 0.35 & 0.04 & 0.52 & 1.00 & & & & & & & & & & & & & & \\
\hline Factor 5 & 0.31 & 0.16 & 0.31 & 0.61 & 1.00 & & & & & & & & & & & & & \\
\hline Factor 6 & 0.33 & 0.04 & 0.35 & 0.55 & 0.48 & 1.00 & & & & & & & & & & & & \\
\hline Factor 7 & 0.31 & 0.05 & 0.21 & 0.38 & 0.65 & 0.42 & 1.00 & & & & & & & & & & & \\
\hline Factor 8 & 0.38 & 0.01 & 0.32 & 0.50 & 0.49 & 0.47 & 0.60 & 1.00 & & & & & & & & & & \\
\hline Factor 9 & 0.26 & 0.01 & 0.29 & 0.42 & 0.58 & 0.47 & 0.54 & 0.57 & 1.00 & & & & & & & & & \\
\hline Factor 10 & 0.21 & 0.14 & 0.41 & 0.23 & 0.45 & 0.36 & 0.36 & 0.38 & 0.45 & 1.00 & & & & & & & & \\
\hline Factor 11 & 0.41 & 0.06 & 0.27 & 0.27 & 0.27 & 0.33 & 0.33 & 0.42 & 0.34 & 0.44 & 1.00 & & & & & & & \\
\hline Factor 12 & 0.38 & 0.06 & 0.45 & 0.60 & 0.42 & 0.52 & 0.35 & 0.38 & 0.25 & 0.31 & 0.56 & 1.00 & & & & & & \\
\hline Factor 13 & 0.29 & -0.08 & 0.41 & 0.67 & 0.50 & 0.58 & 0.52 & 0.53 & 0.48 & 0.32 & 0.29 & 0.65 & 1.00 & & & & & \\
\hline Factor 14 & 0.25 & -0.11 & 0.31 & 0.44 & 0.56 & 0.55 & 0.58 & 0.62 & 0.67 & 0.52 & 0.31 & 0.34 & 0.61 & 1.00 & & & & \\
\hline Factor 15 & 0.35 & -0.14 & 0.26 & 0.35 & 0.35 & 0.46 & 0.42 & 0.58 & 0.58 & 0.43 & 0.42 & 0.35 & 0.38 & 0.58 & 1.00 & & & \\
\hline Factor 16 & 0.47 & 0.14 & 0.37 & 0.32 & 0.29 & 0.35 & 0.28 & 0.40 & 0.29 & 0.41 & 0.47 & 0.30 & 0.27 & 0.33 & 0.54 & 1.00 & & \\
\hline Factor 17 & 0.05 & -0.10 & 0.11 & 0.25 & -0.01 & 0.15 & -0.20 & -0.08 & -0.08 & 0.00 & 0.26 & 0.43 & 0.21 & 0.01 & -0.04 & 0.03 & 1.00 & \\
\hline Factor 18 & -0.11 & -0.07 & 0.04 & 0.20 & 0.12 & -0.04 & -0.18 & -0.10 & -0.02 & -0.13 & -0.21 & 0.05 & 0.03 & -0.10 & -0.10 & -0.07 & 0.44 & 1.00 \\
\hline
\end{tabular}

Note: Factor1: Academic knowledge with proper example; Factor2: Lecture are interesting; Factor3: Learning with fun; Factor4: Communication skill; Factor 5: Different culture acquisition; Factor6: Interpersonal presentation skill; Factor7: Teamwork; Factor8: Selfesteem; Factor9: Adaptation with situation; Factorı: Helpful to each other; Factorı: Peer group to solve problem; Factor12: Want to suggest friends to join in exchange program; Factorıs: Understand requirement of global market; Factori4: Learn to face practical life related challenges; Factor 15: Friendship develop; Factor16: Satisfy with the arrangement; Factori7: Do not feel boar; Factori8: Effective for learning 